\section{CALLING ALL STAR TECHNICIANS}

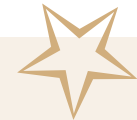

Ivoclar Vivadent are inviting teams of dentists and dental technicians to enter the new IPS e.max Smile Award 2016 with the aim of finding the world's most aesthetic and impressive dental restoration cases using the IPS e.max system.

IPS e.max is the world's most popular and successful all-ceramic system. These users are now being invited to showcase their most impressive dental work.

To be in with a chance of winning, dentists and technicians must register as a team at ipsemax.com/smileaward. Entrants must submit their project online to showcase their finest IPS e.max work, using pictures and videos to successfully demonstrate standards such as high quality aesthetics and excellent dentist and technician collaboration.

A panel of experts will evaluate entries based on aesthetics, complexity and harmony. As aesthetic perception varies across different continents and regions there will be 12 winners. The best three teams of the four regions, Europe/Middle East/Africa, North America/Oceania, Latin America and Asia will be awarded the IPS e.max Smile Award 2016.

The closing date for submissions is 28 February 2016.

For more information on how to enter visit www.ipsemax.com/smileaward or call Ivoclar Vivadent on 01162847880.

\section{THE IMPACT OF DENTINE HYPERSENSITIVITY}

GSK Consumer Healthcare, manufacturers of Sensodyne, hosted a special symposium at the FDI conference, Bangkok to share results of research into the impact of dentine hypersensitivity (DH).

The research used the Dentine Hypersensitivity Evaluation Questionnaire (DHEQ), a validated tool, in order to demonstrate the impact of DH. ${ }^{1,2}$ Through a new pooled analysis of DHEQ data, Sensodyne revealed some surprising findings about how people who experience the condition will compensate, cope and alter their social activities when living with dentine hypersensitivity: ${ }^{3,4}$

- Nine out of ten sufferers had been experiencing the condition for longer than one year

- $70.4 \%$ of DH sufferers considered their sensitivity takes a lot of pleasure out of eating and drinking

- $59.4 \%$ of DH sufferers try to avoid the sensations by biting food into small pieces.

Research also confirmed the clinical benefits of continuous twice-daily use of sensitivity toothpaste. ${ }^{3,4}$

1. Boiko O V, Baker S R, Gibson B J et al. Construction and validation of the quality of life measure for dentine hypersensitivity (DHEQ). J Clin Periodontol 2010; 37: 973-980.

2. Baker S R, Gibson B J, Sufi F, Barlow A, Robinson P G. The Dentine Hypersensitivity Experience Questionnaire: a longitudinal validation study. J Clin Periodontol 2014; 41: 52-59.

3. GSK Data on File RH02026

4. Sufi F, Baker S. The subjective experience of dentine hypersensitivity - a pooled analysis. Presented at the 93rd General Session \& Exhibition of the IADR. 2015. set-up charge for employers signing

up after 23 November 2015, reduced

to $£ 300+V A T$ if they sign up through a

financial adviser

NOW: Pensions has a monthly service charge ranging from $£ 12.50+$ VAT to $£ 36.00+V A T$ depending on the number of employees and whether the employer has a scheme administered by a payroll bureau using the NOW: Pensions' microsite Jon Drysdale, an independent financial adviser from Chartered Financial planners PFM Dental, says: 'Even though your 'staging date' - when you start making contributions to a pension scheme - may be many months away, it makes sense to get your scheme set up as soon as possible to reduce the risk of future set-up or service charges being imposed. It is hard for pension providers to add charges where employers have already signed terms and conditions, so my advice is act now

For more information visit wWW pfmdental.co.uk
If you would like to promote your products or services direct to the dental industry in BDJ Team, call Andy May on 02078434785 or emaila.may@nature.com 